\title{
A novel compact stair-shaped multiband fractal antenna for wireless communication systems
}

\author{
Zain ul Abidin Jaffri ${ }^{1}$, Zeeshan Ahmad ${ }^{2 *}$, \\ Asif Kabir ${ }^{3}$, S. Sabahat H. Bukhari ${ }^{4}$
}

\begin{abstract}
The growing demand for enhanced capacities, broadband services, and high transmission speeds to accommodate speech, image, multimedia, and data communication simultaneously puts a requirement for antenna to operate in multiple frequency bands. A novel compact fractal antenna based on self-similar stair-shaped fractal geometry is proposed in this paper. The fractal antenna is designed by modifying the patch antenna through the iterative process using stair-shaped fractal geometry. The third iteration results in a tri-band response, and the antenna resonate at 3.65, 4.825, and $6.325 \mathrm{GHz}$ with impedance bandwidths of 75.6, 121.2, and $211.4 \mathrm{MHz}$, respectively. The antenna is designed in CST Microwave studio, and evaluated for operating bands and radiation characteristics. Prototype for the third iteration of the fractal antenna is fabricated on FR-4 substrate which is further tested for measured operating bands and radiation characteristics. The simulated and measured results show good agreement.

K e y w o r d s: antenna designing, fractal antenna, multiband, patch antenna, stair-shaped fractal geometry
\end{abstract}

\section{Introduction}

With the continued development in wireless communications, wide operating bandwidths, massive connectivity, high data rates, low latency, and data-intensive applications become inevitable to provide a wide range of services [1]. In general, antenna arrays [2-4] are well-known to meet all these requirements, and provide a number of advantages including increased system capacity, energy efficiency, and robustness etc. However, when it comes to smart devices, it is beneficial to consider a compact single antenna [5]. Therefore, an active research topic has been focused on designing antenna featured by wide operating bandwidth, compact size, lightweight, ease of fabrication, low cost, and multiband frequency operations. Accomplishing these features simultaneously, however, is a major challenge for researchers and antenna designers [6].

The microstrip patch antennas (MPAs) and fractal antennas with wideband and/or multiband characteristics nearly satisfy all the current demands and market needs $[7,8]$. MPA, which is also known as the printed antenna, is a simple patch antenna that consists of a radiated metal foil patch on the top, dielectric substrate, and ground plane. It can be easily fabricated on a printed circuit board (PCB) [9]. The name 'Fractals', which refers to irregular fragments, plays a pivotal role in designing compact and multiband antennas. Fractal shapes possess sets of complex geometries [10,11]. Mandelbrot [12] originally conceived the term fractals to describe a family of complex structural configurations having repeatability in their shapes. Various natural fractal patterns fascinate and motivate researchers toward fractals modeling. Examples of modeling these complicated natural entities include mountain ranges, trees, leaves, ferns, galaxies, coastlines, clouds, boundaries, etc. Design essentials for fractal geometries include iteration order (IO) and iteration factor (IF). Iteration order is the number of iterations performed for creating the particular fractal geometry whereas the iteration factor represents the scaling factor in each iteration [13].

Fractal based designing has been an intensive research topic, and various fractal geometries have been proposed in past decades. The most popular fractal geometries are Koch, Minkowski Sierpinski Gasket and Giuseppe Peano etc, $[14,15]$. Fractal geometries have attracted enormous attention due to their self-similarity and space-filling properties [16,17]. Self-similarity refers to an object which is a mirror image of itself at varying dimensions, whereas space-filling means reduction of the total space occupied by an antenna ie, miniaturization [18]. The performance of the fractal antenna is dependent on several parameters such as gain, return loss, directivity, bandwidth, and VSWR etc, [19].

Designing various shapes of fractal antennas is a new developing orientation in antenna research [20,21]. The demand for a more flexible antenna design with small size, and wideband and /or multiband support is always desired to deal with recent trends in wireless communi-

\footnotetext{
${ }^{1}$ College of Physics and Electronic Information Engineering, Neijiang Normal University, Neijiang 641100, China, ${ }^{2}$ School of Electronic and Information Engineering, Ningbo University of Technology, Ningbo 315211, China, Corresponding author: azee@nbut.edu.cn, ${ }^{3}$ Department of Computer Sciences \& Information Technology, University of Kotli, AJK 11100, Pakistan, ${ }^{4}$ College of Computer Science, Neijiang Normal University, Neijiang 641100, China,
} 


\begin{tabular}{|c|c|c|}
\multicolumn{3}{|c|}{$0^{\text {th }}$ iteration } \\
\hline 1 & 2 & 3 \\
\hline 4 & 5 & 6 \\
\hline 7 & 8 & 9 \\
\hline
\end{tabular}
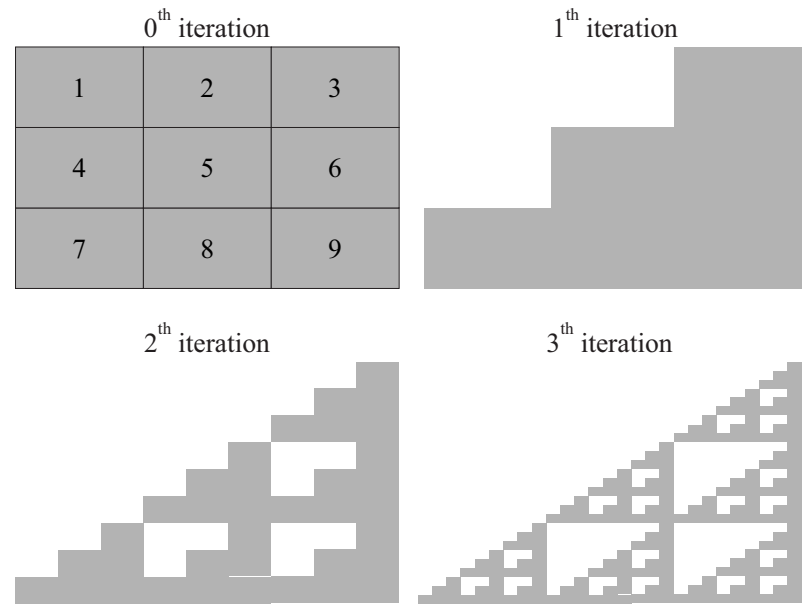

Fig. 1. Illustration of different iterations for the stair-shaped fractal geometry

cation. Recently, various improved antenna designs based on different shapes of natural entities or combining two or more different fractal antennas or a fractal and nonfractal antenna to form a novel antenna have been proposed. In [22], the authors designed an F-shaped fractal antenna for $\mathrm{C}$ - and X-band applications. A rectangular patch antenna with a triangular slot for wireless communication systems is presented in [23]. A novel compact triangular MPA is designed in [24], which can be utilized for wireless communication. An E-shape multiband fractal antenna is proposed in [25], for mobile communication applications. To improve the performance of fractal antennas, it is also suitable to design a shape that is a combination of two or more fractal shapes [26]. The authors in [27] designed a hybrid fractal antenna using three widely used fractal curves Koch, Moore, and Minkowski for multiband operations in wireless communication. The combination of Peano-Gosper, Koch and Minkowski geometries for multi-standard wireless applications is used in [28]. A novel design of a multiband hybrid antenna using Minkowski and invert of Minkowski curves is presented in [29]. In [30], the authors presented a miniaturized hybrid multiband antenna for wireless applications by superimposing two well-known fractal geometries Gosper and Moore. A hybrid antenna design of Minkowski and Sierpinski carpet for multiple wireless applications is proposed in [31]. The authors in $[32,33]$ designed hybrid MPA for wideband and wireless applications. In [34], dual antennas are designed by superimposing dual fractal geometries on each other to achieve desired characteristics and to make them suitable for wireless applications. The combination of three fractal geometries ie, Koch, Minkowski, and Giuseppe Peano is used in [35] to achieve better miniaturization, and performance characteristics. This computed miniaturized hybrid design can operate for multiple frequency bands. An artificial neural network based model for the designing of a dual-band hybrid fractal antenna, constructed by the combination of different fractal geometries for biomedical applications is depicted in [36]. In [37], the authors fused
Moore and Koch fractal geometries to achieve multiband operations. From these previously proposed shapes and combinations, it can be observed that MPA with fractal geometries can be designed for various wireless applications.

In this paper, we demonstrate a novel stair-shaped fractal antenna for multiband operation. A fractal antenna with $\mathrm{IO}=3$ having $\mathrm{IF}=1 / 3$ is presented which is designed in CST Microwave Studio. The prototype of the fractal antenna is fabricated on FR-4 substrate which is further tested for measured operating bands and radiation characteristics. Afterward measured and simulated results are compared.

We deal with the design and demonstrates the stairshaped fractal geometry along with its mathematical description and the stair-shaped fractal antenna design that includes its structural configuration, followed by the fabrication and measurement of a prototype of the fractal antenna. After presenting the results and discussion based on simulations and measurements we compare the proposed antenna with existing antennas in literature.

\section{Design}

\subsection{Stair-shaped fractal geometry}

The stair-shaped fractal geometry can be constructed through an iterative process by following a topology that will lead to the self-similar stair-shaped fractal geometry. We can view the topology of the iterative process pictorially in Fig. 1. Zeroth iteration order of the fractal geometry is a rectangle which is divided into nine identical rectangles and remove three small rectangles at positions 1,2 , and 4 that will result in stair type geometry of first iteration order. For the second iteration, again the same process will be applied and we can continue the subtraction process on the remaining rectangles to get stair-shaped fractal geometry for the second iteration order. We can continue the same process an infinite number of times to obtain the ideal stair-shaped fractal geometry. Fractal geometry up to the 3-rd iteration order has been shown in Fig. 1.

Self-similarity can be observed in stair-shaped fractal geometry as the whole shape of whole fractal geometry is similar to that of its constituent units. Here we can observe that each small rectangle is $\frac{1}{3}$ times its parent rectangle showing an iteration factor of $\frac{1}{3}$. To evaluate the fractal geometry mathematically, let us consider variables namely $n, k$, and $A_{k}$ where $k$ represents iteration order, $n$ represents the total number of small rectangles of $k$-th order and $A_{k}$ represents an overall area of fractal geometry at $k$-th iteration order. From Fig. 1, we can observe the following values of $k$ and $n$ :

$$
\begin{array}{ll}
k=0, & k=1, \quad k=2, \quad k=3, \quad k=4, \ldots \\
n=1, \quad n=6, \quad n=36, \quad n=216, \quad n=1296, \ldots
\end{array}
$$




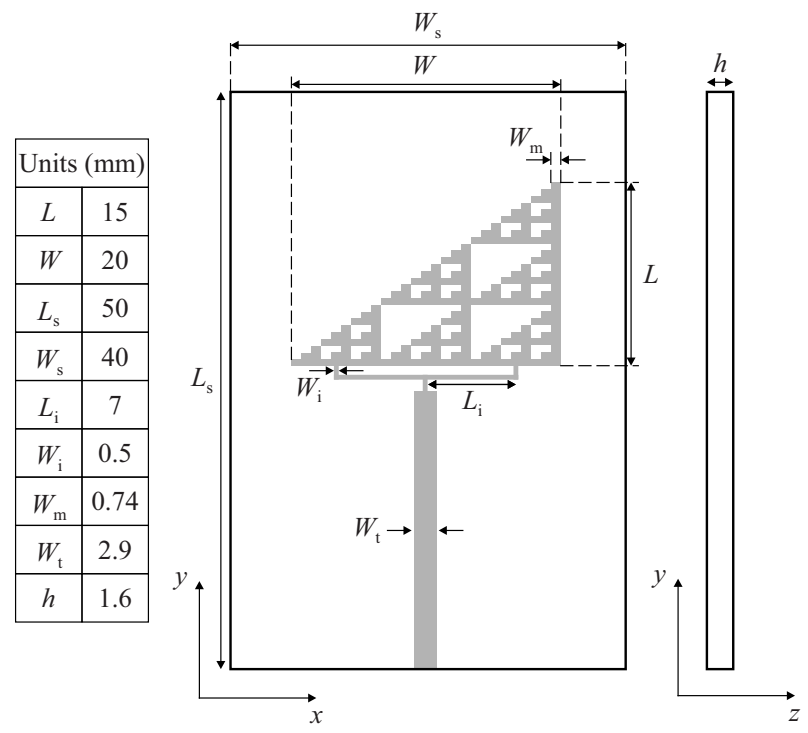

Fig. 2. Schematic diagram of the stair-shaped fractal antenna
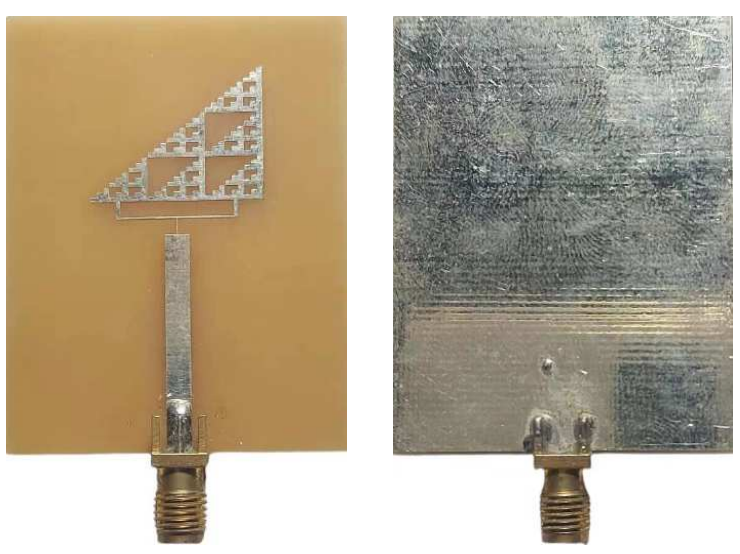

Fig. 3. Photographic front and back view of the fabricated prototype for 3-rd Iteration of the stair-shaped fractal antenna

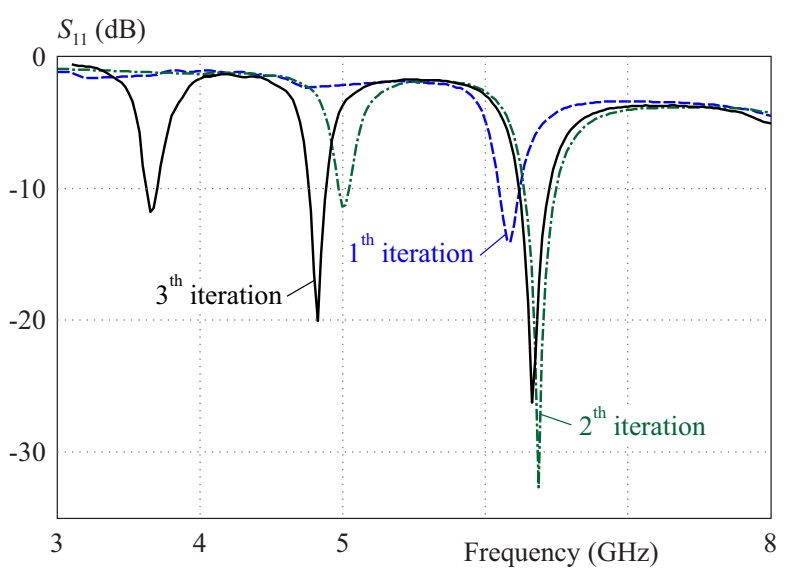

Fig. 4. Simulated return loss versus frequency plot of the stairshaped fractal antenna for the 1-st, 2-nd, and 3-rd iteration

From the sequence above we can observe that we will have $6^{k}$ number of total small rectangles at $k$-th iteration order. Mathematically we can write that:

$$
n=6^{k} .
$$

Similarly, as $k$ increases, the area of overall fractal geometry decrease. If $A_{0}$ is an area of a rectangle at 0 th iteration order, the area of overall fractal geometry at the 1-st iteration is $A_{1}$ which will be $(6 / 9) \times A_{0}$. Similarly, the area of overall fractal geometry at the 2-nd iteration order is $A_{2}$ which equals (6/9) $A_{1}$, and so on. Mathematically, we can write the area of overall fractal geometry at $k$-th iteration order as following

$$
\begin{gathered}
A_{1}=\left[\frac{6}{9}\right]^{1} A_{0} . \\
A_{2}=\left[\frac{6}{9}\right]^{1} A_{1}=\left[\frac{6}{9}\right]^{2} A_{0} . \\
A_{3}=\left[\frac{6}{9}\right]^{1} A_{2}=\left[\frac{6}{9}\right]^{3} A_{0} . \\
A_{4}=\left[\frac{6}{9}\right]^{1} A_{3}=\left[\frac{6}{9}\right]^{4} A_{0} . \\
A_{k}=\left[\frac{6}{9}\right]^{k} A_{0} .
\end{gathered}
$$

\begin{tabular}{|c|c|c|c|}
\hline No & & Description & $\begin{array}{l}\text { Dimension } \\
(\mathrm{mm})\end{array}$ \\
\hline 1 & $L$ & Width of patch & 15 \\
\hline 2 & $W$ & Length of patch & 20 \\
\hline 3 & $L_{s}$ & Length of substrate & 50 \\
\hline 4 & $W_{s}$ & Width of substrate & 40 \\
\hline 5 & $L_{i}$ & Length of half T-feed & 7 \\
\hline 6 & $W_{i}$ & Width of T-feed cut & 0.5 \\
\hline 7 & $W_{m}$ & $\begin{array}{l}\text { Width of small } \\
\text { rectangular cut }\end{array}$ & 0.74 \\
\hline 8 & $W_{t}$ & Width of feed & 2.9 \\
\hline 9 & $h$ & Thickness of substrate & 1.6 \\
\hline
\end{tabular}

Table 1. Dimensions of the stair-shaped fractal geometry for the 3-rd iteration 
Table 2. Frequency versus return loss values of different iterations

\begin{tabular}{ccc}
\hline Iteration & $\begin{array}{c}\text { Frequency } \\
(\mathrm{GHz})\end{array}$ & $\begin{array}{c}\text { Return loss } \\
(\mathrm{dB})\end{array}$ \\
\hline 1-st & 6.19 & -14 \\
\hline \multirow{2}{*}{ 2-nd } & 5.01 & -11.8 \\
& 6.38 & -32.6 \\
\hline \multirow{2}{*}{ 3-rd } & 3.65 & -12.1 \\
& 4.825 & -20.01 \\
& 6.325 & -26.8 \\
\hline
\end{tabular}

Table 3. Comparison between the simulated and measured reflection coefficient of the stair-shaped fractal antenna

\begin{tabular}{ccccccc}
\hline Band & \multicolumn{3}{c}{ Simulated } & \multicolumn{3}{c}{ Measured) } \\
& $\begin{array}{c}\text { Stop } \\
(\mathrm{MHz})\end{array}$ & BW & $\begin{array}{c}\text { Start } \\
(\mathrm{MHz})\end{array}$ & $\begin{array}{c}\text { Stop } \\
(\mathrm{MHz})\end{array}$ & BW \\
\hline 1 & 3623.9 & 3699.5 & 75.6 & 3606 & 3681.2 & 75.2 \\
2 & 4761.6 & 4882.8 & 121.2 & 4780 & 4887 & 107 \\
3 & 6235 & 6446.4 & 211.4 & 6225 & 6450.8 & 225.8 \\
\hline
\end{tabular}

\subsection{Stair-shaped fractal antenna}

The structural configuration of stair-shaped fractal antenna for the 3-rd iteration order is shown in Fig. 2. The antenna is compact having an overall length and width of the radiating patch of $15 \times 20 \mathrm{~mm}$. The length and width of the substrate are $50 \mathrm{~mm}$ and $40 \mathrm{~mm}$, respectively. The smallest dimension within radiating patch at the 3 -rd iteration order is $0.74 \mathrm{~mm}$ that limits the fabrication of any antenna.

A microstrip line $(50 \Omega)$ is used to feed the antenna through a T-shaped section for impedance transformation. Different dimensions of the antenna are tabulated in Tab. 1.

\section{Fabrication and measurement}

The fabricated prototype of the fractal antenna is developed on FR-4 with thickness, dielectric constant, and loss tangent of $1.6 \mathrm{~mm}, 4.3$, and 0.025 , respectively. A $50 \times 40 \mathrm{~mm}$ substrate is used having a thickness of $1.6 \mathrm{~mm}$ with a copper deposition thickness of $34.65 \mu \mathrm{m}$. SMA connector is used as an input port for the antenna. The fabricated prototype can be viewed in Fig. 3 .

Table 4. Simulated and measured gain of the stair-shaped fractal antenna at different operating bands

\begin{tabular}{cccc}
\hline $\begin{array}{l}\text { Operating } \\
\text { band }\end{array}$ & $\begin{array}{c}\text { Frequency } \\
(\mathrm{GHz})\end{array}$ & $\begin{array}{c}\text { Simulated } \\
\text { gain }(\mathrm{dB})\end{array}$ & $\begin{array}{c}\text { Measured } \\
\text { gain }(\mathrm{dB})\end{array}$ \\
\hline 1 & 3.65 & 2.37 & 2.393 \\
2 & 4.82 & 4.31 & 4.338 \\
3 & 6.32 & 2.81 & 2.864 \\
\hline
\end{tabular}

Table 5. Comparison of the proposed stair-shaped fractal antenna with existing antennas for different No of operating frequency bands

\begin{tabular}{cccc}
\hline Ref & No & $\begin{array}{c}\text { Gain } \\
(\mathrm{dB})\end{array}$ & $\begin{array}{c}\text { antenna }) \\
\left(\mathrm{mm}^{2}\right)\end{array}$ \\
\hline$[38]$ & 5 & 4.4 & $100 \times 100$ \\
{$[39]$} & 3 & 8.76 & $100 \times 100$ \\
{$[16]$} & 3 & 8.1 & $173 \times 70$ \\
{$[40]$} & 3 & 7.1 & $220 \times 190$ \\
{$[41]$} & 3 & 5.7 & $96 \times 72$ \\
{$[42]$} & 3 & 2.1 & $67.2 \times 36.5$ \\
{$[43]$} & 2 & 5.40 & $200 \times 200$ \\
{$[44]$} & 2 & 4 & $100 \times 50$ \\
{$[45]$} & 2 & 6.74 & $80 \times 80$ \\
{$[46]$} & 2 & 2.8 & $63 \times 43.6$ \\
{$[47]$} & 2 & - & $130 \times 100$ \\
{$[15]$} & 1 & 6 & $80 \times 80$ \\
{$[48]$} & 1 & 7.16 & $100 \times 100$ \\
{$[49]$} & 1 & 8.5 & $100 \times 100$ \\
{$[50]$} & 1 & -1.0 & $120 \times 100$ \\
{$[51]$} & 1 & 6 & $183 \times 360$ \\
{$[52]$} & 1 & 8.91 & $223 \times 174$ \\
{$[53]$} & 1 & -1.1 & $130 \times 100$ \\
{$[54]$} & 1 & 2.3 & $70 \times 70$ \\
{$[55]$} & 1 & 6 & $66 \times 25$ \\
\hline Proposed & 3 & 4.33 & $50 \times 40$ \\
antenna & & & \\
\hline & & &
\end{tabular}

The reflection coefficient of the prototype is measured using Agilent E8362B vector network analyzer (VNA) and radiation characteristics at operating frequencies were measured in an anechoic chamber.

\section{Results and discussions}

In this section, we evaluate the performance of the proposed antenna, where both simulated and experimental results are considered. The fractal antenna is designed and simulated in CST Microwave Studio. The simulation results are further verified experimentally through VNA and anechoic chamber.

Simulated reflection coefficient versus frequency response for the 1-st, 2-nd and 3-rd iteration order is shown in Fig. 4. The $S_{11}$ also known as reflection coefficient or return loss is an important parameter to witness the radiation efficacy of an antenna. In the 3-rd iteration, we can see that there are three frequencies at which the $S_{11}$ value is less than $-10 \mathrm{~dB}$. The minimum observed value of the reflection coefficient is -20.01 at $4.825 \mathrm{GHz}$. Table 2 shows the return loss values of different iterations of our proposed antenna design. We can also observe that operating bands directly relate to the iteration order $(k)$ of the antenna.

We will focus on antenna design for the 3-rd iteration order having triple-band frequency response shown in Fig. 4. We can observe a triple-band response with resonant frequencies centered at 3.65, 4.825, and $6.325 \mathrm{GHz}$. 


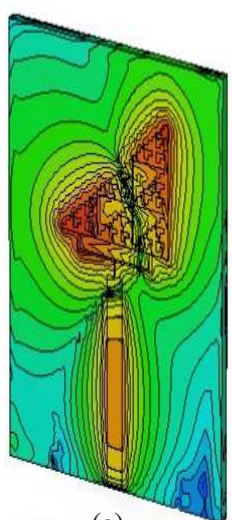

(a)

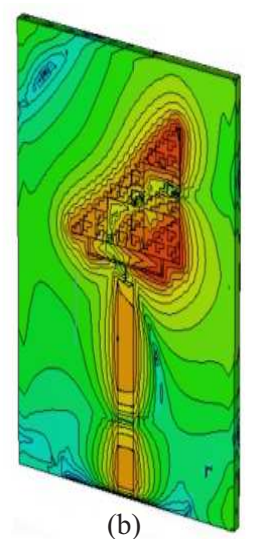

(b)

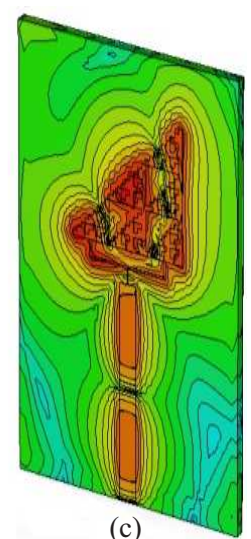

(c)

Fig. 5. Current distribution at (a) $-3.65 \mathrm{GHz}$ (b) $-4.825 \mathrm{GHz}$ (c) $-6.325 \mathrm{GHz}$

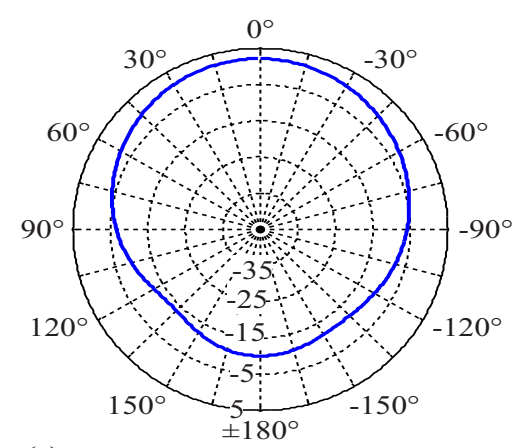

(a)

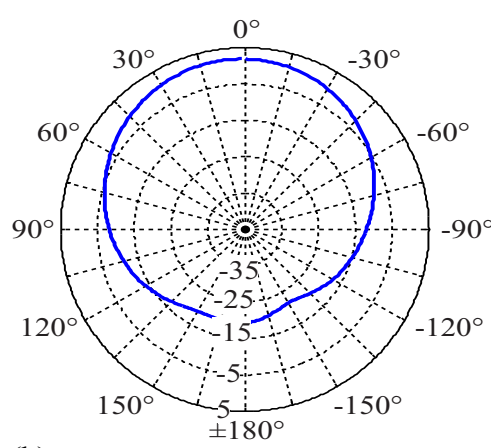

(b)

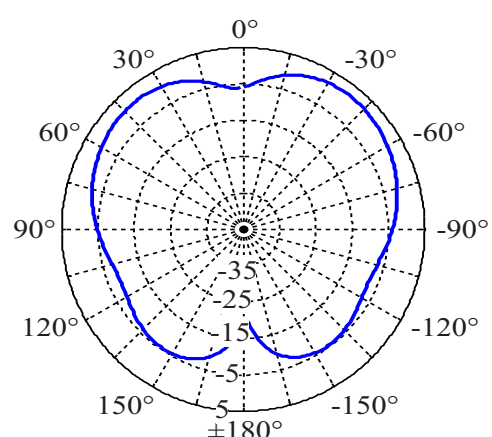

(c)

Fig. 6. Simulated radiation pattern at (a) $-3.65 \mathrm{GHz}$ (b) $-4.825 \mathrm{GHz}$ (c) $-6.325 \mathrm{GHz}$
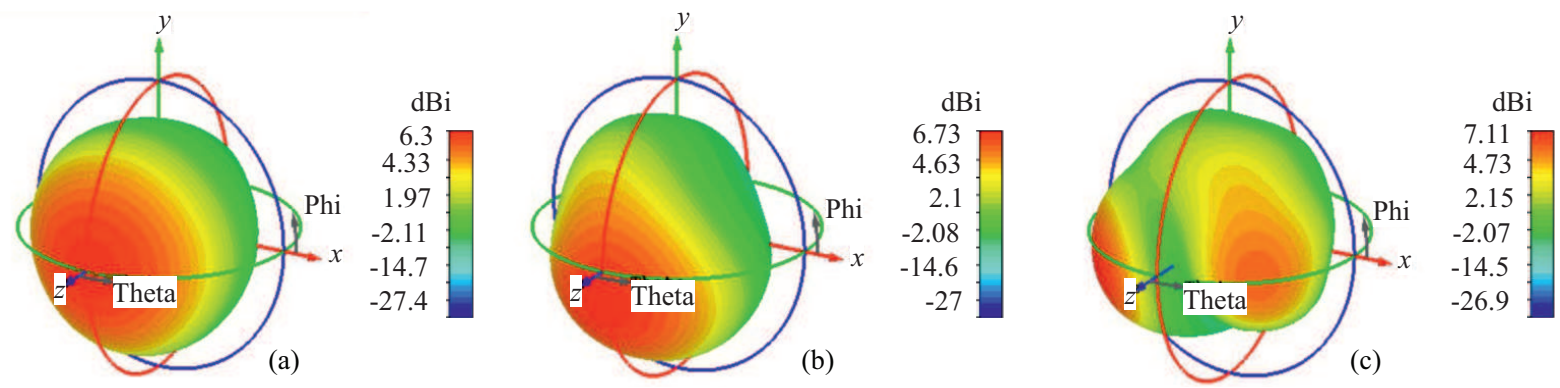

Fig. 7. Directivity of the stair-shaped fractal antenna at (a) $-3.65 \mathrm{GHz}$ (b) $-4.825 \mathrm{GHz}(\mathrm{c})-6.325 \mathrm{GHz}$

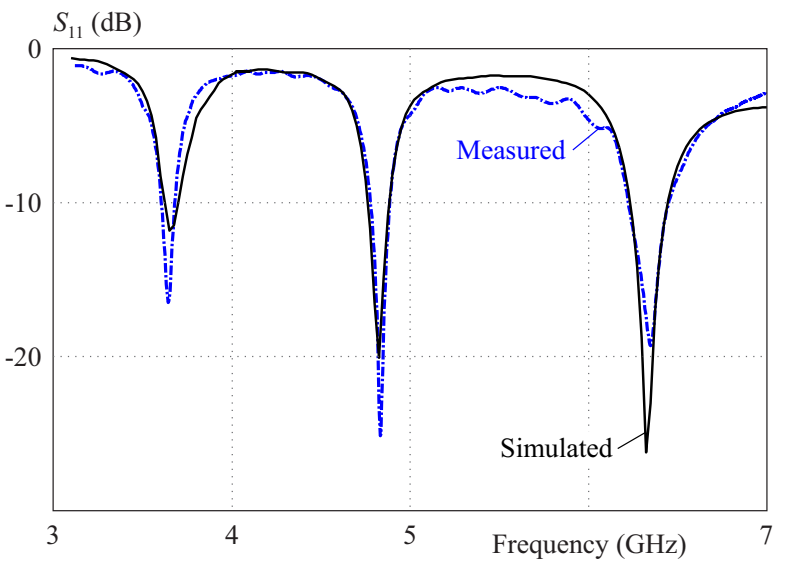

Fig. 8. Measured and simulated reflection coefficient of the stairshaped fractal antenna
The surface current distribution shows the distribution of current density at various locations of the patch. It represents the current density at different operating frequencies. The plots of surface current distribution at resonant frequencies $(3.65,4.825$, and $6.325 \mathrm{GHz})$ are depicted in Fig. 5(a), (b), and (c). It is observed that the current distribution is mostly concentrated in the feed line and the stair-shaped design in the patch. The current is also distributed in the rest of the grounded patch.

Simulated radiation patterns at operating frequencies are presented in Fig. 6. Here, it can be observed that the pattern of the antenna is directional and the antenna is radiating in a broadside direction with directivity of 6.27 , 6.54 , and $7.1 \mathrm{dBi}$ at operating frequencies of $3.65,4.825$, 
and $6.325 \mathrm{GHz}$, respectively. The three-dimensional (3D) directivity plots can be seen in Fig. 7 .

Next, the fabricated prototype of the fractal antenna is tested for operating bands through Agilent E8362B VNA. The measured and simulated reflection coefficients are compared in Fig. 8. It can be observed that the measured resonant frequencies are $3.65,4.825$, and $6.325 \mathrm{GHz}$ with impedance bandwidth $(-10 \mathrm{~dB})$ of $75.2,107$, and $225.8 \mathrm{MHz}$, respectively. The measured results can be seen to be in good agreement with those simulated. The comparison results of the simulated and measured reflection coefficients of the stair-shaped fractal antenna are summarized in Tab. 3.

The simulated 3D gain of $2.37,4.31$, and $2.81 \mathrm{~dB}$ at three different operating frequencies are shown in Fig. 9. The maximum value of the simulated gain is $4.31 \mathrm{~dB}$ which is achieved at $4.82 \mathrm{GHz}$. The simulated gain values of the fabricated prototype of the stair-shaped fractal antenna within operating bands are given in Tab.4.

Similarly, the radiation pattern of the fabricated prototype of the fractal antenna is tested at measured resonant frequencies in an anechoic chamber. Anechoic chamber ( $700 \mathrm{MHz}$ to $40 \mathrm{GHz}$ ) available at the National University of Science and Technology, Pakistan is used for testing radiation patterns of the fabricated antenna. Normalized radiation patterns of the fabricated antenna at measured resonant points ie, $3.65,4.825$, and $6.325 \mathrm{GHz}$ are given in Fig. 10, and the corresponding 3D measured radiation patterns are plotted in Fig. 11. Here, we can observe that measured patterns of the fabricated antenna are also directional, and the antenna is radiating in a broadside direction. Good agreement can also be observed in simulated and measured radiation characteristics of the fractal antenna. The measured gain of the fabricated proto-

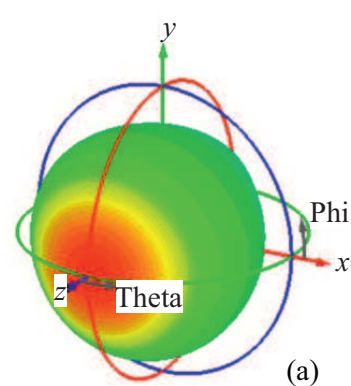

(a)

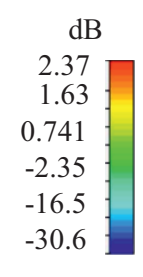

ios
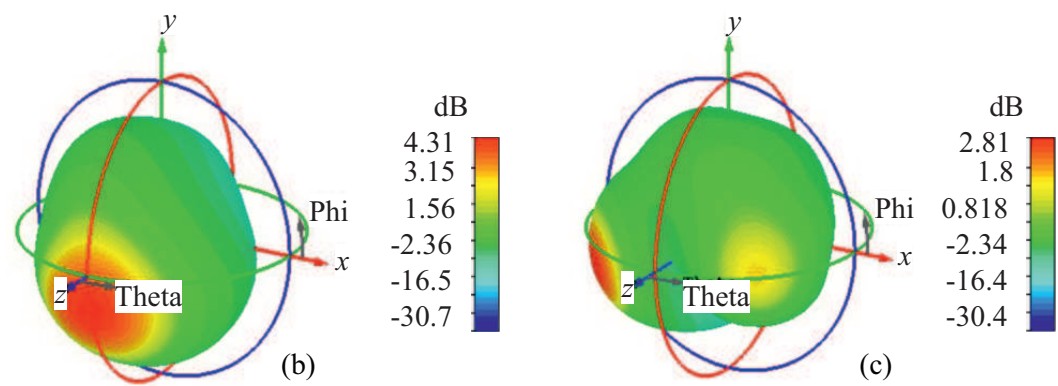

Fig. 9. Simulated 3D gain of 2.37, 4.31 , and $2.81 \mathrm{~dB}$ at (a) $-3.65 \mathrm{GHz}$ (b) $-4.825 \mathrm{GHz}$ (c) $-6.325 \mathrm{GHz}$

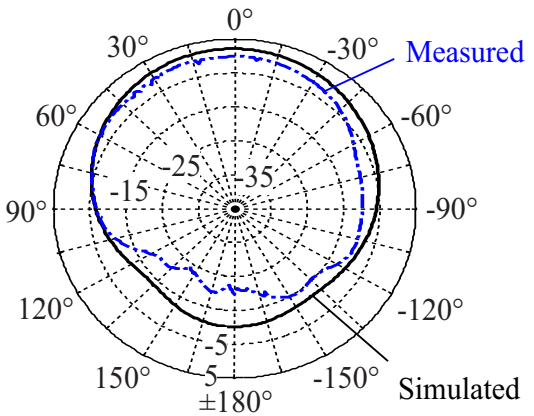

(a)

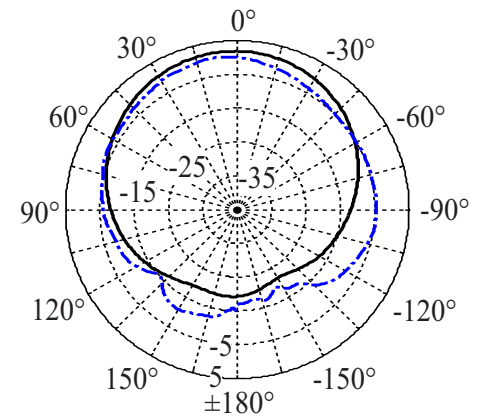

(b)

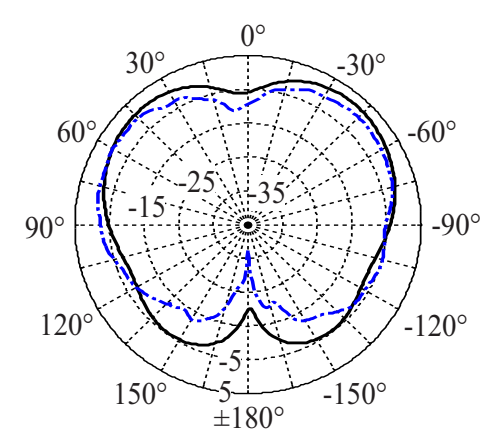

(c)

Fig. 10. Simulated and measured radiation patterns at: (a) $-3.65 \mathrm{GHz}$, (b) $-4.825 \mathrm{GHz}$, and (c) $-6.325 \mathrm{GHz}$

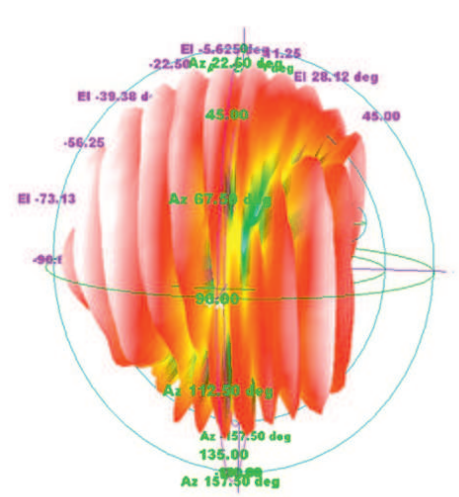

(a)

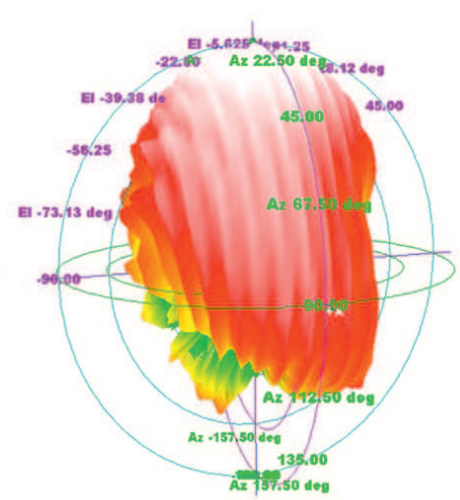

(b)

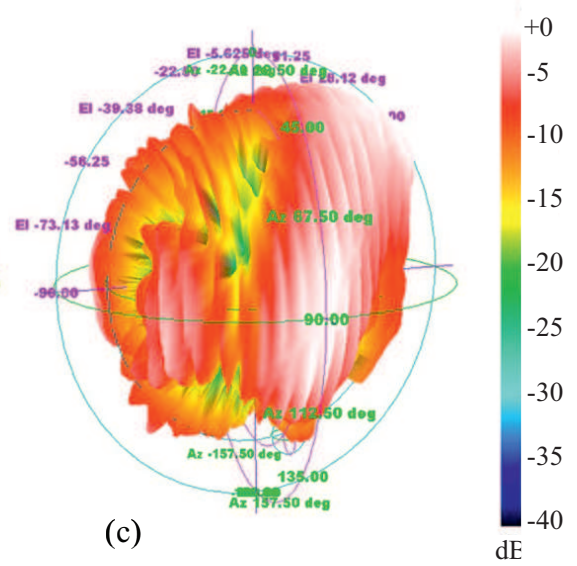

Fig. 11. Measured 3D radiation patterns from anechoic chamber at: (a) $-3.65 \mathrm{GHz},(\mathrm{b})-4.825 \mathrm{GHz}$, and (c) $-6.325 \mathrm{GHz}$ 
type of the stair-shaped fractal antenna within operating bands is given in Tab. 4.

It can also be observed that there is a slight variation in simulated and measured results, which may be due to the following reasons:

1) In simulations, the thickness of conducting part of the antenna which includes the ground plane and patch is kept to be $35 \mathrm{~m}$ but in fabrication thickness of conducting part of the PCB is $34.65 \mu \mathrm{m}$.

2) Another reason for the slight variation in results can be attributed to the soldering effect which results in certain losses and detuning of the antenna.

3) The lowest dimension that is etched to fabricate the 3 -rd iteration of the fractal antenna is $0.74 \mathrm{~mm}$. This extremely small dimension is very difficult to etch. Variation in such portions of antennas can also cause variation in simulated and fabricated results.

4) After etching slots/cuts on the patch, slot edges become rough which may cause the results to change slightly.

5) Edges of substrate and ground plane should be sharp in fabricated antenna similar to the simulated one but in reality, the edges and corners of the ground and substrate are not that sharp.

Moreover, the anechoic chamber used to measure the radiation patterns also have some imperfections such as signal leakage from various sources, unwanted reflections, and diffractions, which may degrade the quality of results.

\section{Comparison}

Table 5 depicts the characteristics of the proposed antenna with existing antennas of the approximate same size designed by employing a simple fractal or a hybrid technique. Comparison is made based on the number of operating frequency bands, maximum gain, and the size of the antenna.

\section{Conclusion}

A novel compact fractal antenna based on self-similar stair-shaped fractal geometry is proposed in this paper. Simulated and measured results for the proposed antenna are discussed in detail. The incorporation of stairshaped fractal geometry resulted in a tri-band response, and the antenna is resonating in three bands having measured resonant frequencies of 3.65, 4.825, and $6.325 \mathrm{GHz}$. Measured impedance bandwidths at these frequencies are $60 \mathrm{MHz}(3660-3600 \mathrm{MHz}), 107 \mathrm{MHz}(4887-4780 \mathrm{MHz})$, and $225.8 \mathrm{MHz}(6450.8-6225 \mathrm{MHz})$, respectively. Different parameters of the fractal antenna including return loss, impedance bandwidths, and far-field characteristics at various operating bands are discussed. Good agreement has been observed in measured and simulated results of the proposed antenna that enables the designed fractal antenna a good candidate for multiband applications. The three operating bands centered at 3.5, 4.7, and $6.3 \mathrm{GHz}$, can be used in Wi-Max, C-band applications, and finally point-to-point high-speed wireless communications. New fractal geometries can be designed and tested for higher iterations in the future to achieve more efficient antennas in terms of size reduction, attaining wider bandwidth, and accomplishing multiband operation.

\section{REFERENCES}

[1] N. Rao and V. Dinesh Kumar, "Miniaturization of microstrip patch antenna for satellite communication: A novel fractal geometry approach," Wireless Personal Communications, vol. 97, no. 3, pp. 3673-3683, 2017. doi: 10.1007/s11277-017-4691-4.

[2] H. Zeng, Z. Ahmad, J. Zhou, Q. Wang, and Y. Wang, "DOA estimation algorithm based on adaptive filtering in spatial domain," China Communications, vol. 13, no. 12, pp. 49-58, 2016. doi: 10.1109/CC.2016.7897554.

[3] Z. Ahmad, Y. Song, and Q. Du, "Wideband DOA estimation based on incoherent signal subspace method," COMPEL-The International Journal for Computation and Mathematics in Electrical and Electronic Engineering, vol. 37, no. 3, pp. 1271-1289, 2018. doi: 10.1108/COMPEL-10-2017-0443.

[4] Q. Du, Y. Song, C. Ji, and Z. Ahmad, "Digital beamforming for ultra-wideband signals utilizing an extrapolated array generated by Carathodory representation combining fractional delay filters based on high-order Hermite interpolation," IEEJ Transactions on Electrical and Electronic Engineering, vol. 13, no. 12, pp. 1760-1768, Jun. 2018. doi: 10.1002/tee.22738.

[5] S. Tripathi, A. Mohan, and S. Yadav, "A compact UWB Koch fractal Antenna for UWB antenna array applications," Wireless Personal Communications, vol. 92, no. 4, pp. 1423-1442, Aug. 2016. doi: 10.1007/s11277-016-3613-1.

[6] H. Oraizi and S. Hedayati, "Miniaturization of microstrip antennas by the novel application of the Giuseppe Peano fractal geometries," IEEE Transactions on Antennas and Propagation, vol. 60, no. 8, pp. 3559-3567, 2012.

doi: 10.1109/tap.2012.2201070.

[7] C. Wang, M. Shih and L. Chen, "A wideband open-slot antenna with dual-band circular polarization," IEEE Antennas and Wireless Propagation Letters, vol. 14, pp. 1306-1309, 2015. doi: 10.1109/lawp.2015.2403572.

[8] M. Abdalla, A. Ibrahim and A. Boutejdar, "Resonator switching techniques for notched ultrawideband antenna in wireless applications," IET Microwaves, Antennas $\&$ Propagation, vol. 9, no. 13, pp. 1468-1477, 2015. doi: 10.1049/iet-map.2014.0838.

[9] D. Yu, S. Gong, Y. Wan and W. Jiang, "Wideband conical-beam circularly polarized microstrip antenna for large ground plane," IEEE Transactions on Antennas and Propagation, vol. 63, no. 10, pp. 4614-4619, 2015. doi: 10.1109/tap.2015.2464086.

[10] V. Reddy and N. Sarma, "Compact circularly polarized asymmetrical fractal boundary microstrip antenna for wireless applications," IEEE Antennas and Wireless Propagation Letters, vol. 13, pp. 118-121, 2014. doi: 10.1109/lawp.2013.2296951.

11] C. Puente-Baliarda, J. Romeu, R. Pous and A. Cardama, "On the behavior of the Sierpinski multiband fractal antenna," IEEE Transactions on Antennas and Propagation, vol. 46, no. 4, pp. 517-524, 1998. doi: 10.1109/8.664115.

$12]$ B. Mandelbrot, "Fractals, form, chance, and dimension WH Freeman and Co." San Francisco zbMATH, 1977.

13] W.-L. Chen, G.-M. Wang, and C.-X. Zhang, "Bandwidth enhancement of a microstrip-line-fed printed wide-slot antenna with a fractal-shaped slot," IEEE Transactions on Antennas and Propagation, vol. 57, no. 7, pp. 2176-2179, 2009. doi: 10.1109/tap.2009.2021974. 
[14] A. Azari, "A new super wideband fractal microstrip antenna," IEEE Transactions on Antennas and Propagation, vol. 59, no. 5, pp. 1724-1727, 2011. doi: 10.1109/tap.2011.2128294.

[15] M. Islam, M. Cho, M. Samsuzzaman and S. Kibria, "Compact antenna for small satellite applications [antenna applications corner]," IEEE Antennas and Propagation Magazine, vol. 57, no. 2, pp. 30-36, 2015. doi: 10.1109/map.2015.2420471.

[16] A. Amini, H. Oraizi and M. C. Zadeh, "Miniaturized UWB log-periodic square fractal antenna," IEEE Antennas and Wireless Propagation Letters, vol. 14, pp. 1322-1325, 2015. doi: 10.1109/lawp.2015.2411712.

[17] C.-L. Liu, Y.-F. Lin, C.-M. Liang, S.-C. Pan and H.-M. Chen, "Miniature internal penta-band monopole antenna for mobile phones," IEEE Transactions on Antennas and Propagation, vol. 58, no. 3, pp. 1008-1011, 2010. doi: 10.1109/tap.2009.2039309.

[18] H. Malekpoor and S. Jam, "Analysis on bandwidth enhancement of compact probefed patch antenna with equivalent transmission line model," IET Microwaves, Antennas \&5 Propagation, vol. 9, no. 11, pp. 1136-1143, 2015. doi: 10.1049/iet-map.2014.0384.

[19] A. Jamil, M.Z. Yusoff, N. Yahya and M.A. Zakariya, "A compact multiband hybrid Meander-Koch fractal antenna for WLAN USB dongle," in IEEE Conference on Open Systems, Langkawi, Malaysia, 2011, pp. 290-293. doi: 10.1109/ICOS.2011.6079295.

[20] S. Sran and J. Sivia, "ANN and IFS based wearable hybrid fractal antenna with DGS for S, C and X band application," AEU - International Journal of Electronics and Communications, vol. 127, p. 153425, 2020. doi: 10.1016/j.aeue.2020.153425

[21] A. Jamil, M. Yusoff and N. Yahya, "Analysis of a hybrid fractal curve antenna using the segmentation method," Engineering Reports, vol. 2, no. 11, 2020. doi: 10.1002/eng2.12263.

[22] D. Kaur and J. S. Sivia, "Design of F-shape fractal microstrip patch antenna for C- and X-band applications." in Proceedings on Advances in Soft Computing, Intelligent Systems and Applications, Springer, Singapore, 2018, pp. 199-207. doi: 10.1007/978 -981-10-5272-9_19.

[23] U. Chakraborty, S. Chatterjee, S. K. Chowdhury and P. P. Sarkar, "Triangular slot microstrip patch antenna for wireless communication." in 2010 Annual IEEE India Conference (INDICON), Kolkata, India, 2010, pp. 1-4. doi: 10.1109/INDCON.2010.5712747.

[24] J. Singh, A. P. Singh and T. S. Kamal, "On the design of triangular microstrip antenna for wireless communication," International Journal of Computer Applications-IJCA, pp. 103-106, 2011.

[25] N. Bayatmaku, P. Lotfi, M. Azarmanesh and S. Soltani, "Design of simple multiband patch antenna for mobile communication applications using new E-shape fractal," IEEE Antennas and Wireless Propagation Letters, vol. 10, pp. 873-875, 2011. doi: 10.1109/lawp.2011.2165195.

[26] J. Jacobs, "Efficient resonant frequency modeling for dual-band microstrip antennas by gaussian process regression," IEEE Antennas and Wireless Propagation Letters, vol. 14, pp. 337-341, 2015. doi: 10.1109/lawp.2014.2362937.

[27] I. Bangi and J. Sivia, "Moore, Minkowski and Koch curves based hybrid fractal antenna for multiband applications," Wireless Personal Communications, vol. 108, no. 4, pp. 2435-2448, 2019. doi: 10.1007/s11277-019-06531-7.

[28] N. Sharma, S. Bhatia and V. Sharma, "Peano-Gosper, Koch and Minkowski fractal curves-based novel hybrid antenna using modified partial ground plane for multi-standard wireless applications," Journal of Electromagnetic Waves and Applications, pp. 1-21, 2021. doi: 10.1080/09205071.2021.1925974.

[29] A. Singh, J. S. Sivia and K. Kaur, "Multiband hybrid microstrip patch antenna for L, S and C band applications," International Journal of Control Theory and Applications, vol. 10, no. 6, pp. 503-509, 2017.

[30] K. Kaur and J. Sivia, "A compact hybrid multiband antenna for wireless applications," Wireless Personal Communications, vol. 97 , no. 4 , pp. 5917-5927, 2017.

doi: $10.1007 / \mathrm{s} 11277-017-4818-7$.

31] N. Sharma, V. Sharma and S. Bhatia, "A novel hybrid fractal antenna for wireless applications," Progress In Electromagnetics Research $M$, vol. 73, pp. 25-35, 2018. doi: $10.2528 /$ pierm18052403.

[32] N. Sharma and V. Sharma, "A design of microstrip patch antenna using hybrid fractal slot for wideband applications," Ain Shams Engineering Journal, vol. 9, no. 4, pp. 2491-2497, 2018. doi: 10.1016/j.asej.2017.05.008.

[33] S. Jindal, J. Sivia and H. Bindra, "Hybrid fractal antenna using Meander and Minkowski curves for wireless applications," Wireless Personal Communications, vol. 109, no. 3, pp. 1471-1490, 2019. doi: 10.1007/s11277-019-06622-5.

[34] I. Bangi and J. Sivia, "Minkowski and Hilbert curves based hybrid fractal antenna for wireless applications," $A E U$ - International Journal of Electronics and Communications, vol. 85, pp. 159-168, 2018. doi: 10.1016/j.aeue.2018.01.005.

[35] M. Kaur and J. Sivia, "Minkowski, Giuseppe Peano and Koch curves based design of compact hybrid fractal antenna for biomedical applications using ANN and PSO," AEU - International Journal of Electronics and Communications, vol. 99, pp. 14-24, 2019. doi: 10.1016/j.aeue.2018.11.005.

36] M. Kaur and J. Sivia, "ANN-based design of hybrid fractal antenna for biomedical applications," International Journal of Electronics, vol. 106, no. 8, pp. 1184-1199, 2019. doi: 10.1080/00207217.2019.1582712.

[37] N. Sharma and S. S. Bhatia, "Split ring resonator based multiband hybrid fractal antennas for wireless applications," $A E U$ - International Journal of Electronics and Communications, vol. 93, pp. 39-52, 2018. doi: 10.1016/j.aeue.2018.05.035.

38] S. Dhar, K. Patra, R. Ghatak, B. Gupta and D. R. Poddar, "A dielectric resonator-loaded Minkowski fractal-shaped slot loop heptaband antenna," IEEE Transactions on Antennas and propagation, vol. 63, no. 4, pp. 1521-1529, 2015. doi: 10.1109/TAP.2015.2393869.

39] D. Sankaranarayanan, D. Venkatakiran and B. Mukherjee, "A novel compact fractal ring based cylindrical dielectric resonator antenna for ultra wideband application," Progress In Electromagnetics Research C, vol. 67, pp. 71-83, 2016. doi: 10.2528/PIERC16062007.

40] J. Anguera, E. Martínez-Ortigosa, C. Puente, C. Borja and J. Soler, "Broadband triple-frequency microstrip patch radiator combining a dual-band modified Sierpinski fractal and a monoband antenna," IEEE Transactions on Antennas and Propagation, vol. 54, no. 11, pp. 3367-3373, 2006. doi: 10.1109/TAP.2006.884209.

[41] A. Mehdipour, I. D. Rosca and A. R. Sebak, "Full composite fractal antenna using carbon nano-tubes for multiband wireless applications," IEEE Antenna Wireless and Propagation Letters, vol. 9, pp. 891-894, 2010. doi: 10.1109/LAWP.2010.2076342.

[42] J. S. Sivia, G. Kaur and A. K. Sarao, "A modified sierpinski carpet fractal antenna for multiband application," Wireless Personal Communications, vol. 95, no. 4, pp. 4269-4279, 2017. doi: 10.1007/s11277-017-4079-5

[43] S. Behera and K. J. Vinoy, "Multi-port network approach for the analysis of dual band fractal microstrip antennas," IEEE Transactions on Antennas and Propagation, vol. 60, no. 11, pp. 5100-5106, 2012. doi: 10.1109/TAP.2012.2208085.

[44] Y. K. Choukiker, S. K. Sharma and S. K. Behera, "Hybrid fractal shape planar monopole antenna covering multiband wireless communications with MIMO implementation for handheld mobile devices," IEEE Transactions on Antennas and Propagation, vol. 62 , no. 3 , pp. 1483-1488, 2014. doi:10.1109/TAP.2013.2295213.

[45] D. V. Kiran, D. Sankaranarayanan, and B. Mukherjee, "Compact embedded dual-element rectangular dielectric resonator 
antenna combining Sierpinski and Minkowski fractals," IEEE Transactions on Components, Packaging and Manufacturing Technology, vol. 7, no. 5, pp. 786-791, 2017. doi: 10.1109/TCPMT.2017.2690463.

[46] M. A. Kenari, M. N. Moghadasi, R. A. Sadeghzadeh, B. S. Virdee and E. Limiti, "Dual-band RFID tag antenna based on the Hilbert-curve fractal for HF and UHF applications," IET Circuits Devices System, vol. 10, no. 2, pp. 140-146, 2016. doi: 10.1049/iet-cds.2015.0221.

[47] N. Abdullah, M. A. Arshad, E. Mohd, and S. A. Hamzah, "Design of Minkowski fractal antenna for dual band applications," in Proceedings on Advances in Soft Computing, Intelligent Systems and Applications, Singapore, 2018, pp. 199-207.

[48] M. Shrinivasulu, P. R. Prajapati and M. V. Kartikeyan, "Realization of circularly polarized microstrip antenna using fractal," in National Conference on Recent Advances in Electronics 83 Computer Engineering, Roorkee, India, 2015, pp. 138-142.

[49] S. Abulgasem, F. Tubbal, R. Raad, P. I. Theoharis, S. Liu and M. U. A. Khan, "A wideband metal-only patch antenna for CubeSat," Electronics, vol. 10, no. 1, pp. 50, 2021. doi: 10.3390/electron-ics10010050.

[50] Z. W. Yu, G. M. Wang, X. J. Gao, and K. Lu, "A novel small-size single patch microstrip antenna based on Koch and Sierpinski fractal-shapes," Progress in Electromagnetics Research Letters, vol. 17, pp. 95-103, 2010. doi: 10.2528/PIERL10062803.
[51] M. N. A. Karim, M. K. Abd Rahim, H. A. Majid, O. Ayop, M. Abu and F. Zubir, "Log periodic fractal Koch antenna for UHF band applications," Progress In Electromagnetics Research, vol. 100, pp. 201-218, 2010. doi: 10.2528/PIER09110512.

[52] G. Srivatsun, S. S. Rani and G.S. Krishnan, "A self-similar fractal Cantor antenna for MICS band wireless applications," Wireless En-gineering and Technology, vol. 2, no. 2, pp. 107-111, 2011. doi: 10.4236/wet.2011.22015.

[53] W. L. Chen, G. M. Wang and C. X. Zhang, "Small-size microstrip patch antennas combining Koch and Sierpinski fractal-shapes," IEEE Antennas and Wireless Propagation Letters, vol. 7, pp. 738-741, 2008. doi: 10.1109/LAWP.2008.2002808.

[54] H. Orazi and H. Soleimani, "Miniaturization of the triangular patch antenna by the novel dual-reverse- arrow fractal," IET Microwaves, Antennas \&S Propagation, vol. 9, no. 7, pp. 627-633, 2015, doi: 10.1049/ietmap.2014.0462.

[55] Y. K. Choukiker and S. K. Behera, "Design of wideband fractal antenna with combination of fractal geometries," in International Conference on Information, Communications \&s Signal Processing, Singapore, 2011, pp. 1-3, doi: 10.1109/ICICS.2011.6174226.

Received 8 August 2021 